\title{
REVIEW OF DENTAL IMPRESSION MATERIALS
}

\author{
R.G. CRAIG \\ Department of Biomaterials, School of Dentistry, University of Michigan, Ann Arbor, Michigan 48109
}

Adv Dent Res 2(1):51-64, August, 1988

\section{ABSTRACT}

$\mathbf{M}$ ajor advances in impression materials and their application have occurred during the last decade, with greater emphasis being placed on rubber impression materials than on dental compound, zinc oxide-eugenol, and agar and alginate. Of particular interest has been the effect of disinfection solutions on the qualities of impressions and the biocompatibility of impression materials. The principal advance in hydrocolloids has been the introduction of the agar/alginate impression technique, which has simplified the procedure and improved the quality of gypsum dies compared with those prepared in alginate impressions. The tear strength of some alginates has been improved, and some have been formulated so that the powder is dustless, thus reducing the health hazard as a result of patient inhalation of dust during the dispensing process. Polyether and silicone impression materials have been modified so that the working time, viscosity, and flexibility of the polyethers have been improved and, with the introduction of addition silicones, their accuracy has become exceptional. Although the early addition silicones liberated hydrogen after setting, thus delaying the pouring of models and dies, most addition silicones have been improved so that no hydrogen is released and dies can be poured immediately. The introduction of automatic mixing systems for addition silicones has simplified their manipulation, has reduced the number of voids in impressions, and has reduced the amount of material wasted. The incorporation of surfactants into addition silicones has made them hydrophilic, with wetting properties similar to those of polyethers, and has made pouring bubble-free gypsum dies easier.

This review is confined to published and unpublished information of the past decade. It will also suggest trends that should be anticipated in the near future based on this information. The review will not present information developed before 1975, which is available in several textbooks on dental materials by Craig (1985a), Phillips (1982), and Williams and Cunningham (1979).

\section{Rigid IMPRESSION MATERIALS}

\section{IMPRESSION COMPOUND}

The use of dental tray compound has decreased with the increased substitution of acrylic tray materials. The application of dental impression compound has also decreased with the increased use of rubber impression materials, which can also be electroformed to produce metal dies. However, impression compound is useful for checking cavity preparations for undercuts and for making impressions of full crown preparations where gingival tissues must be displaced. Excessive temperature rise of the pulp chamber is undesirable, and Grajower et al. (1975) recently measured temperature increases in the pulp when

Presented at the International State-of-the-Art Conference on Restorative Dental Materials, September 8-10, 1986, National Institute of Dental Research compound impressions of crown preparations were taken in copper bands. They measured temperatures of up to $53^{\circ} \mathrm{C}$ when the bands were heated in an uncontrolled manner, $\angle 44^{\circ} \mathrm{C}$ when bands were flamed under controlled conditions for about one min, and to about $41^{\circ} \mathrm{C}$ when the bands were heated for seven min in $52^{\circ} \mathrm{C}$ water. No graininess was observed at a magnification of $10 \times$ for this last condition. Temperature measurements showed that when the impression cools on its own, the pulp temperature is $>37.5^{\circ} \mathrm{C}$ for more than three min. Chilling should start as soon after seating as possible, and chilling times of approximately 20 and $30 \mathrm{sec}$ were recommended for copper band impressions of incisors and molars.

\section{ZINC OXIDE-EUGENOL}

Although zinc oxide-eugenols are excellent materials for wash impressions of edentulous areas, they have been replaced to a large extent by light-bodied 
rubber impression materials. As a result of the diminished use, research papers on zinc oxide-eugenol impression pastes have been nearly non-existent.

There has been an increased interest in the disinfection of dental impressions, and Olsson et al. (1982) reported the effect of disinfection solutions on the dimensional stability and surface detail of Luralite, Momax, and Opotow zinc oxide-eugenol impressions. The disinfectants were aqueous solutions of Cidex ( $2 \%$ glutaraldehyde), Tecno-sept ( $0.7 \%$ ampholytic soap $+4 \%$ propanol-2), Hibitane (0.5\% chlorhexidine), K-644 (2.4\% mixture of chlorinated sodium phosphate and potassium bromide), Chloramine ( $5 \%$ sodium salt of p-toluene sulfanchloroamide), Benzalkon ( $1 \%$ benzalkonium chloride), and Surface phenol derivate (0.5\% mixture of 2-phenyl phenol and chlorocresol). No significant influence on accuracy or surface detail was observed after one hr of exposure to the disinfectant, and small but clinically insignificant changes in dimensions occurred after impressions were stored in air for $24 \mathrm{hr}$ after disinfection.

\section{HYDROCOLLOID IMPRESSION MATERIALS}

\section{AGAR}

Sawyer et al. (1976) and Lehmann and Behrend (1984) measured the accuracy of agar impressions and stone models prepared from these impressions, using laboratory models simulating a three-unit fixed bridge. In the former study, Kerr Hydrocolloid was compared with Kerr Alginate, Coe Alginate, and Impregum (polyether). The average of five stone casts from these impressions showed the agar material to be substantially more accurate than the alginates and only slightly less accurate than the polyether. The authors stated that the accuracy of the alginates was clinically unacceptable. In the second study, which used Surgident and Van $R$ agar, the distances between the abutments on the stone casts were within $0.02 \mathrm{~mm}$ of the master model.

The accuracy of 11 agar impression materials was compared with that of eight alginate and one addition silicone systems of light, regular, and heavy viscosity (Jørgensen, 1982a). He demonstrated that, as a class, the agar impression materials were more accurate than the alginates and the addition silicone. However, if the addition silicone impressions were heated to mouth temperature and poured in a mix of stone at mouth temperature, they were the most accurate.

One of the complaints about agar has been the complexity of the technique and possibly lower-thandesirable tear strength. Campagni et al. (1985) described a simplified method where the liquefied heavybodied agar is back-loaded into a disposable syringe, stored for at least five min at $145-155^{\circ} \mathrm{F}$, and then injected into a wet field. After injection, liquefied heavy-bodied agar in a tray tempered at $105^{\circ} \mathrm{F}$ is placed over the syringed agar. With this technique, only the heavy-bodied material needs to be liquefied, higher tear strengths result, and moisture control is not a problem.

\section{AGAR/ALGINATE}

The principal simplification in the agar impression technique has been the introduction of the combined agar/alginate method. Papers by Appleby et al. (1980, 1981), Fusayama et al. (1982), Herring et al. (1984), and Johnson and Craig (1986a) have described the technique, and measured the accuracy and reproduction of detail and bond strength between combinations of agars and alginates.

The general procedure is to heat the agar-supplied in glass cartridges, disposable plastic syringes, or cylinders to be placed into re-usable syringes - for about six min in boiling water. The agar is stored for at least $10 \mathrm{~min}$ at $65^{\circ} \mathrm{C}$ before being syringed around the preparations. A mix of alginate containing $10 \%$ more water than normally recommended is placed in a tray, and it is immediately seated over the agar syringe material. The cool mix of alginate helps gel the agar, and when the alginate has set, the combined impression is removed. The technique simplifies the use of agar and provides an impression surface that allows for preparation of stone casts acceptable for crown and bridge applications.

Studies of accuracy of the agar/alginate combination impressions vary in detail, but all conclude that the accuracy is satisfactory for clinical use in crown and bridge applications. Bond strength measurements of the agar to the alginate have demonstrated that some combinations give higher values than others, and some combinations show adhesive failure, while others fail cohesively in the agar. Bond strengths of from 400 to $1000 \mathrm{~g} / \mathrm{cm}^{2}$ were readily obtainable with compatible agar/alginate combinations, while bond strengths of $200 \mathrm{~g} / \mathrm{cm}^{2}$ or less for incompatible systems were found to be inadequate. The study by Fusayama et al. (1982) found that the agar/alginate combination allowed for reproduction of a $10-\mu \mathrm{m}$ line in dental stone and was comparable to polysulfides and silicone impressions in reproduction of detail.

An in vitro study of accuracy of agar-alginate combination impressions by Appleby et al. (1985) showed no statistical difference in accuracy between impressions made with alginates especially developed for this technique and conventional alginates. The bond strengths of agar-alginate combinations could not be correlated to their dimensional stability. It was concluded that the agar-alginate combinations were sufficiently accurate for single restorations but are questionable for multiple units.

\section{ALGINATE}

\section{Composition}

The potential toxicity of alginate powders has attracted some attention. De Freitas (1980) analyzed 25 dental alginate powders. The lead content of 20 products was low and varied from 0.0007 to $0.095 \%$, while 
Unijel with ATA, DP Cream, Kromopan, Palgat, and CA 37 had values of $1.58,8.76,9.40,11.7$, and $14.8 \%$, respectively. Zinc concentrations ranged from 0.0014 to $6.05 \%$, with Unijel II, AB 44, Coe, Kerr, and Jeltrate having the highest values of $2.65,2.80,3.03,3.42$, and $6.05 \%$, respectively. Concentrations of barium were between 0.1 and $0.75 \%$, with Tissuetex and Verex having values of $1.1-1.3 \%$. Cadmium was usually present at levels $<0.0005 \%$ except for DeTrey and Jeltrate, which contained about $0.02 \%$. The alginate powders contained fluoride as $\mathrm{Na}_{2} \mathrm{SiF}_{6}$ in concentrations from 0.3 to $4 \%$, with most of the values being from $1-3 \%$. The $\mathrm{Na}_{2} \mathrm{SiF}_{6}$ is added to improve the surface quality of dental stone poured against the set alginate. Of the elements, lead poses the greatest potential for toxicity. The lead salts are present partly to replace calcium to enhance the gel by the formation of lead alginate; however, they are not essential in the formulation of a high-quality alginate. The risk to the dental patient from extraction of lead, even from those alginates with the highest concentrations during impression-taking, is minimal. However, ingestion of portions of these alginates could present a problem. The most serious concern about the toxicity of lead would be with respect to dental personnel from inhalation of dust from the alginate powder.

Woody et al. (1977), Brune and Beitesbrekke (1978), and Knibbs and Piney (1985) have characterized the airborne particles and assessed the levels of airborne particles of alginate impression materials. Woody et al. (1977) found that $10-15 \%$ of the particles were siliceous fibers of $<3 \mu \mathrm{m}$ in diameter and $>20 \mu \mathrm{m}$ in length. The dimensions of these particles are similar to asbestos fibers, glass, and $\mathrm{Al}_{2} \mathrm{O}_{3}$, that produce fibrogenesis and carcinogenesis. Based on this evidence it was recommended that inhalation of dust from alginate be avoided.

The levels of dust collected $40 \mathrm{~cm}$ above containers of alginate powder that had been shaken by hand for $30 \mathrm{sec}$ and immediately opened were found by Brune and Beltesbrekke (1978) to be $1.3-2 \mathrm{mg} / \mathrm{m}^{3}$. The threshold limit for a short-time exposure of $15 \mathrm{~min}$ is $0.45 \mathrm{mg} \mathrm{Pb} / \mathrm{m}^{3}$, which is twice the value of $0.2 \mathrm{mg}$ $\mathrm{Pb} / \mathrm{m}^{3}$ for an alginate containing $10 \%$ lead. Dust levels were measured close to the nose and mouth of the operator for one dustless (Blueprint, DeTrey, Dentsply) and seven standard alginates. The 20-minute time-weighted averages for the standard alginates varied from 6.5 to $17.8 \mathrm{mg} / \mathrm{m}^{3}$, while no detectable amount could be measured for the dustless alginate. Although data have not been reported for dust levels of dustless alginate (Jeltrate Plus, L.D. Caulk/Dentsply), comparable results would be expected, since it is similar to Blueprint. Unpublished information indicates that these alginate powders are made dustless by the application of a coating of a glycol.

A second approach to provision of a dustless alginate is the two-paste system Ultrafine. The base paste contains all the usual ingredients plus water $(70 \%)$ and a silicone oil minus the calcium sulfate. The calcium sul- fate is contained in the catalyst paste plus water $(60 \%)$ and a thickening agent. A comparison of this material with conventional alginates has been reported by Williams and Watkins (1983) and Eames and Litvak (1984), who observed that it had higher tear and compressive strengths than did conventional alginates and, in spite of the presence of the humectant, no improvement in dimensional stability.

Davis and Preble (1986) studied the accuracy of alginate-silicone impressions for use in partial denture construction where undercuts were present and the taper on the preparations was minimal. They found the casts prepared with the alginate-silicone material to be inaccurate compared with the master model or casts prepared with a condensation silicone impression material.

Unpublished data by Craig (1986a) confirm the higher tear strength of $600 \mathrm{~g} / \mathrm{cm}^{2}$ compared with values of 360 and $530 \mathrm{~g} / \mathrm{cm}^{2}$ for Jeltrate and Jeltrate Plus, respectively. The higher value for Jeltrate Plus has been accomplished by an increase in the alginate concentration; this change does not alter the percent permanent deformation or strain but does increase the compressive strength by about $75 \%$. Storage of Ultrafine in air for $15 \mathrm{~min}$ results in a shrinkage of about $1 \%$, compared with a value of $0.15 \%$ for Jeltrate Plus.

\section{Dispensing}

Alginate powder is supplied in packages for single impressions or in bulk. When supplied in bulk, it is usually hermetically sealed in a metal can or tightly sealed in a plastic can with a plastic screw top. It is also vacuum-packed in a laminated plastic-foil bag (Proof, Kerr).

The accurate dispensing of alginate powder from a bulk container affects the properties of the impression material. Moor (1985) has shown that variations as great as 30\% exist, depending on the method of dispensing. However, when recommended dispensing procedures were followed, no significant difference existed between the weights of powder from individual packages and that dispensed from bulk for a single impression.

Caswell et al. (1986) found that volumetric dispensing of alginate powders could differ from the recommended weight by from 10 to $20 \%$ and depending on the method of dispensing may vary by as much as $28 \%$. They recommend, in the absence of weighing the powder, fluffing the powder by rotating and tumbling the can, dipping the scoop, tapping the scoop gently with the spatula, and leveling the powder in the scoop with a spatula.

\section{Mixing}

The effect of mechanical versus hand-mixing of alginates on porosity and properties has been studied by Koski (1977) and Reisbick et al. (1982). Koski (1977) showed that the fewest bubbles resulted when the Whip-Mix vacuum mechanical spatulator was used, followed by the Columbus system centrifugal me- 
chanical spatulator, and hand spatulation. However, no significant differences were found in accuracy among the three methods. Unpublished data by Craig (1986a) showed no increase in density of hand mixes and those prepared with the Columbus system; however, the Columbus system was a major convenience when impressions were taken of a large number of athletes in a mouth-protector program.

More recently, Reisbick et al. (1982) evaluated the effect of using the Cadco Alginator, the Whip-Mix vacuum spatulator, and hand-mixing on properties of alginates. The vacuum-mixing method resulted in the fewest bubbles. Both the mechanical and hand mixes had a large number of small bubbles, with the hand mixes also containing large bubbles. In spite of these differences, there were no clinically relevant differences in percent permanent deformation or strain. They found placement of the mix of alginate into the impression tray to be the most critical step with respect to bubbles.

\section{Setting Characteristics}

Harcourt (1978) used a reciprocating rheometer to study the setting process of alginates and a number of rubber impression materials. Working time was the time from the start of mixing to the first change in slope of the rheometer tracing, and the setting time was the time when no further decrease in oscillations occurred. However, these times do not always agree with the clinical working and setting times.

More recently, Ellis and Lamb (1981) used a rebound resilience instrument to determine the rebound resilience $t_{g}$ (gelation time) on $t_{e}$ (equilibrium rebound resilience time). The temperature-dependence of the reaction process was of the Arrhenius type, and the reaction involving the gelation process had a different activation energy than did the process involving the development of the elasticity. They showed that $t_{e}$ could be twice as long as $t_{g}$ and thus identified the time the material should remain in the mouth after setting has started (loss of tackiness). They also showed that as much as a $25 \%$ decrease in $t_{e}$ could occur by increasing the temperature of the mix water from 21 to $25^{\circ} \mathrm{C}$.

Although it is well-recognized that alginate impressions shrink in dry air, the syneresis in moist air is not always appreciated. Miller (1975) measured shrinkage from syneresis of 12 alginates from $10 \mathrm{~min}$ to $24 \mathrm{hr}$. Dimensional change at one $\mathrm{hr}$ varied from +0.16 to $-0.44 \%$, with most products having values of about $-0.1 \%$. At $24 \mathrm{hr}$, values varied from -0.15 to $-1.28 \%$, with most of the products having changes in dimensions of -0.5 to $-0.7 \%$. When stored in liquid paraffin, five of the 12 products shrank the same as if stored in air, while the others contracted much less.

\section{Accuracy}

The accuracy of the new syringe-tray alginates (Algi$X$, Ardent, and Ultrafine) for crown and bridge appli- cations was compared with that of an agar/alginate combination, two agar syringe-tray materials, and one light- and heavy-bodied addition silicone (Hansson and Eklund, 1984). The in vitro study measured distances between abutments, and between abutments and the periphery of the five types of trays. They found that, in most clinical situations, the new alginates were as accurate as the other hydrocolloids when used in either perforated or nonperforated metal stock trays, but severe inaccuracies were observed when disposable plastic trays were used. The agar/alginate combination was less accurate than the alginates when multiple abutments were present. However, when narrow spaces with severe unblocked undercuts are found, the alginates may be inferior to agar or silicone.

The effects of impression trays on the accuracy of stone casts prepared from alginate impressions have been reported by Woodward et al. (1985) and Mendez (1985). It was demonstrated by Woodward et al. (1985) that alginate impressions made in perforated trays were more accurate than those made in rim-lock trays. The comparison of loose- versus tight-fitting trays was inconclusive. For the loose-versus tight-fitting perforated trays, half the data favored a loose-fitting tray and half showed no difference, while for the rim-lock trays only one of six dimensions showed any difference between loose- and tight-fitting trays. The study by Mendez (1985) also reported that perforated stock or custom trays produced more accurate horizontal dimensions than did nonperforated trays. The vertical dimensions (depth of the palatal vault) were reproduced most accurately by the rim-lock nonperforated tray, closely followed by the stock perforated tray and custom nonperforated tray. For the stock perforated tray, the impressions generally were slightly undersized, while they were oversized for the others.

Periodically, claims have been made that alginate impressions can be stored for $24 \mathrm{hr}$ before being poured without problems of inaccuracies (e.g., JLB). An accuracy study by Brugirard (1983) on Calginat claims than when the material is stored according to manufacturer's directions, pouring may be delayed for up to $24 \mathrm{hr}$; however, the dimensional changes at 12 and $24 \mathrm{hr}$ were 0.06 and $0.13 \%$, respectively.

\section{Techniques}

Hollinger et al. (1984) conducted a laboratory and clinical study of alginate impression techniques. The techniques included alginate with a tray-compoundadhesive, a tray-compound, and a tray alone. Horizontal dimensions on maxillary and mandibular impressions were almost always larger than the master, with the unsupported tongue space on the mandibular impression having the largest changes of +3 to $+4 \%$. They observed clinically that the alginate impressions taken with the tray-compound-adhesive technique were the most accurate.

Moskowitz et al. (1984) demonstrated that an alginate impression allows for a critical evaluation of tooth 
preparations in relation to final impressions. It can also be used to fabricate temporary immediate provisional restorations while the processed indirect provisional restorations are fabricated.

\section{Compatibility with Gypsum Products}

Jarvis and Earnshaw $(1980,1981)$ reported on the effects of alginate on the surface of cast gypsum. They showed that the effect is both physical and chemical and varies with the alginate product. Poor surfaces on casts consisted of unreacted $\mathrm{CaSO}_{4} \cdot 1 / 2 \mathrm{H}_{2} \mathrm{O}$ to a depth of $80 \mu \mathrm{m}$, while the best surfaces consisted of considerable amounts of potassium calcium sulfate plus small amounts of $\mathrm{CaSO}_{4} \cdot 2 \mathrm{H}_{2} \mathrm{O}$ and $\mathrm{CaSO}_{4} \cdot 1 / 2$ $\mathrm{H}_{2} \mathrm{O}$. The small amounts of a potassium salt present in the alginate as an accelerator did not significantly alter the surface of the cast, but $\mathrm{Na}_{2} \mathrm{SO}_{4}$ that was formed as a by-product of the setting reaction of the alginate caused the poor surfaces. Sufficient $\mathrm{Na}_{2} \mathrm{SO}_{4}$ is present to retard the setting of $\mathrm{CaSO}_{4} \cdot 1 / 2 \mathrm{H}_{2} \mathrm{O}$, especially in mixes of low water-to-powder ratios, such as improved stones. They recommended that efforts be made to formulate alginates to reduce the concentrations of sodium and sulfate ions in the exudate formed on the surface of the set alginate.

Carlyle (1983) and Eames et al. (1978) reported on the compatibility of gypsum products with alginates and agars. Both showed that various combinations of hydrocolloid and gypsum products had variations in compatibility and that attention should be paid to selection of a compatible pair.

The compatibility of 10 alginates with seven dental gypsum products was evaluated by Owen (1986). None of the combinations, and only four alginates, were able to reproduce a $0.020 \mathrm{~mm}$ line. Thirty-four of 70 combinations could reproduce a $0.050-\mathrm{mm}$ line, eight could transfer a 0.075 - $\mathrm{mm}$ line, and the remaining 38 combinations could not reproduce any of the three lines. Varied results were observed with alginates treated with fixing solutions.

Morris et al. (1983) demonstrated that smoothing the surface of the mixed alginate with a wet finger, prior to making the impression, consistently resulted in fewer bubbles on the surfaces of casts.

Otani et al. (1985) showed that shifting the $\mathrm{pH}$ of alginate mixes that are normally alkaline to neutral or slightly acidic $(\mathrm{pH} \sim 6)$ improved the quality and reproduction of detail of stone casts. They suggest re-formulation of alkaline alginates to shift the $\mathrm{pH}$ to a more optimal level.

\section{Diffusion of Fluoride from Alginates}

Several papers have studied the absorption and diffusion of fluoride from alginate impression materials. Whitford and Ekstrand (1980) found that plasma levels of fluoride $30 \mathrm{~min}$ after routine alginate impressions were 2.6 times above controls, urinary excretion rates of fluoride had increased 2.9 times during the first two hr, and whole saliva levels at $15 \mathrm{~min}$ were 100 times over controls. When small amounts of al- ginate were injected, plasma and urinary levels increased sharply.

Hattab and Frostell (1980) found fluoride uptake of surface enamel $(5 \mu \mathrm{m})$ exposed five $\mathrm{min}$ to an alginate containing $1.9 \% \mathrm{~F}$ to be significant $(\sim 600 \mathrm{ppm})$, while the second $6-\mu \mathrm{m}$ layer had a fluoride uptake of 140 ppm. Later, Hattab and Linden (1985) showed that diffused fluoride was not directly related to the total fluoride content or the bulkiness of the alginate. LeCompte and Whitford (1981) compared surface enamel fluoride levels 15 min after alginate impressions and APF gel treatment and found an average increase of $800 \mathrm{ppm}$ for alginate and $8000 \mathrm{ppm}$ for APF gel.

\section{Disinfection of Alginates}

Bergman et al. (1985) found that immersion of alginate impressions in disinfectant solutions for one hr caused unacceptable changes in surface detail and accuracy. When the alginates were sprayed with the disinfectant solutions, all had acceptable dimensional stability; however, only surfaces sprayed with Cidex, Techno-sept, and chloramine showed no deterioration in surface detail.

\section{DUPLICATING COMPOUNDS}

The accuracy of hydrocolloid duplicating material was compared with a silicone and a polyether product (Finger, 1986). No correlation between accuracy and stiffness was found, and for reduction of the risk of the fracture of investment or gypsum casts, materials with low stiffness are recommended. The rubber materials are recommended as duplicating materials when a refractory die-investing technique for fixed-cast restorations is to be used, while the agar materials can be readily used in the preparation of partial dentures.

\section{RUBbER IMPRESSION MATERIALS}

Major advances have occurred in the past decade in the area of elastic impression materials, probably the most important being the development of the addition silicone system. General reviews of rubber impression materials by Craig (1977), Harcourt (1978), and McCabe and Storer (1980) have been published, as have a status report on polyethers (Council on Dental Materials and Devices, 1977) and an appraisal of addition silicone impression materials (McCabe and Wilson, 1978). A comparison of 12 manufacturers' addition silicone systems with three polyethers, two polysulfides, and two condensation silicone systems has been published (Craig, 1986a).

\section{MANIPULATION}

The number of voids in mixes of rubber impression materials before and after syringing as well as the effect of mechanical and static mixing on voids and properties has been reported. Stackhouse (1983) found 
that neither hand or mechanical mixing completely eliminated bubbles but that a mechanical mixer ( $\mathrm{Co}-$ lumbus) resulted in mixes with the fewest bubbles and also greatly reduced the working time. The best hand-mixing method used stropping over a larger area of the pad and a flexible spatula. In a later study (Stackhouse, 1985), he found that syringes with smaller orifices at the tip resulted in significantly fewer bubbles, as did extrusions from the second half of a syringe full of rubber impression material. Kishimoto et al. (1980) compared manual and air-operated impression syringes with polysulfide and polyether materials. Although they found no significant difference in bubble entrapment with manual or air-operated syringes, the air-activated syringe was more easily controlled. Hambrok (1981) evaluated a mechanical mixing process and found that it reduced variables in dispensing and mixing and also allowed for adaptation to specific clinical requirements. A static automatic dispensing and mixing system for a lowviscosity addition silicone (Express) was evaluated by Craig (1985b), and he found about one-fourth the number of bubbles obtained with hand mixes of the same material. Initially, the catalyst and base were the same color, and uniform mixing was verified by observation of no difference in properties with hand and the automatic static mixes. Recently, low- and regular-viscosity types are available, with the catalyst and base being different colors; again, the static mixing system gave uniform mixes. A combination mechanical and static mixer has been recently introduced for another addition silicone (President-Coltène). Evaluation of the regular viscosity (Craig, 1986a) has demonstrated excellent mixes with minimum bubbles and physical and mechanical properties comparable with those of hand mixes of regular President.

A comparison of the densities of hand versus mechanical-vacuum spatulation (Vac-U-Vestor) of a polysulfide (Permlastic), an addition silicone (Reprosil), and an alginate (Ultrafine) was reported by Scrabeck et al. (1986). The average densities of the mechanical-vacuum mixes were greater than those of hand mixes by $0.4,4.0$, and $1.2 \%$, respectively, for the polysulfide, addition silicone, and alginate; however, none of the differences was statistically significant at the $95 \%$ level of confidence.

\section{SETTING CHARACTERISTICS}

The rheological properties of rubber impression materials have been reported. Koran et al. (1977), using a Brookfield viscometer, found that low-viscosity polysulfide (Permlastic) and condensation silicone (Elasticon) functioned as Newtonian materials just after being mixed, while several other polysulfides (CoeFlex, Omniflex, and Unilastic) were non-Newtonian. Herfort et al. (1977) confirmed that Omniflex exhibited extreme shear-thinning, as did a polyether (Impregum). They found that viscosity characteristics were a function of filler content. McCabe and Bowman (1981) used an extrusion rheometer to measure the viscosity of a variety of polysulfide and condensation silicones and a polyether and observed that all materials were pseudoplastic, with viscosity decreasing with increasing shear rates. Their data did not correlate well with setting and working time data from a reciprocating rheometer.

The polymerization of elastomeric impression materials was studied by Cook (1982a, b, c) using rheological methods. He found that the polymerization kinetics of the polysulfides appeared to be first-order with respect to coupling agent and water and possibly with thiol groups. Problems related to the concentration of water in the original pastes, the exact functionality, and the possibility that the reaction may be diffusion-controlled prevented a more definite statement. The data for condensation silicones could be fitted to kinetic equations, but the kinetics was not consistent with the stoichiometry. However, the dependence of reaction rate on catalyst-base ratio was qualitatively consistent with kinetic and network considerations. The reaction of polyethers was first-order with respect to monomer and initiator concentrations at high catalyst-base ratios but not when initiator concentrations were low as a result of decreases in initiating and propagating species. A detailed analysis of addition silicones was not possible because of lack of information on concentrations and functionality; however, the results were qualitatively consistent with kinetics and network structure.

Arikawa et al. (1982) developed a pulsating rheometer and found that the rheometric tracings yielded estimates of working and setting times that agreed better with clinical times than did values from the continuous oscillating rheometer, since it was more sensitive to changes in rheological properties for the few minutes after mixing. De Araujo et al. (1985) used a cone-and-plate rheometer to examine the rheological properties in tension of a polyether, two addition silicones, and a polysulfide. Calculated elastic recovery times after tensile deformation of $24 \%$ were shown to agree with the manufacturers' stated setting times.

Modification of the setting times of addition silicones was accomplished by Stannard and Craig (1979) by retarding the polymerization by addition of molecules containing carbon triple bonds such as phenylpropiolic acid. The retarder was extremely effective, with $0.01 \mathrm{~g}$ per $20 \mathrm{~g}$ mix retarding setting for an additional three min and $0.05 \mathrm{~g}$ per $20 \mathrm{~g}$ of mix retarding the setting for $48 \mathrm{hr}$.

The properties of three addition silicone products supplied with retarders were evaluated by Stannard and Sadighi-Nouri (1986). The addition of retarders slowed the rate of increase in viscosity for standard mixes of catalyst and base, while it reduced or left unchanged the initial viscosity. For one product, increasing the ratio of catalyst to base increased the rate of development of viscosity, while for another the rate of increase in the viscosity decreased. This unusual effect is most likely caused by differences in viscosity of the base and catalyst and a change in the 
ratio of vinyl to hydride groups. Although the retarder systems are effective, increases in the time the impression materials are left in the mouth are essential so that the permanent deformation at the time of removal does not become unduly large.

\section{ELASTIC AND VISCOELASTIC PROPERTIES}

These qualities have been measured by Goldberg (1974), Kaloyannides and Christidou (1975), Tolley and Craig (1978), and Inoue and Wilson (1978a, b). Creep compliance showed that for compressive stresses up to about $12 \mathrm{~N} / \mathrm{cm}^{2}$, the polysulfides, silicones, and polyethers demonstrated linear viscoelastic behavior. The permanent deformation was highest for the polysulfides, followed by polyethers, condensation silicones, and addition silicones. The elastic compliance and percent strain between 100 and 1000 $\mathrm{g} / \mathrm{cm}^{2}$ was highest for polysulfides, followed by condensation silicones, addition silicones, and polyethers. The percent flow was the highest for polysulfides, followed by condensation silicones, with the polyethers and addition silicones being the lowest.

Tests for elastic and viscoelastic properties are frequently conducted on samples held at $32^{\circ} \mathrm{C}$ for the time specified for the impression to be left in the mouth. Sandrik and Sarna (1980) showed that $32^{\circ} \mathrm{C}$ is an unrealistic temperature, since rubber impression materials reached $32^{\circ} \mathrm{C}$ in $1.6 \mathrm{~min}$ and $35^{\circ} \mathrm{C}$ in $4.5 \mathrm{~min}$ at mouth conditions. They recommended that samples be held at $37^{\circ} \mathrm{C}$.

The elastic and viscoelastic properties of addition silicones as a function of composition were reported by Williams and Craig (1984) and Williams (1984). Increasing the hydride polymer (crosslinker)-vinyl polymer ratio decreased the percent permanent set, percent strain, and creep, while increasing the elastic modulus; for the polymers used, these effects became quite small for ratios higher than 3:1. Increases in filler content from 10 to $30 \mathrm{wt} \%$ also decreased percent permanent set, percent strain, and creep and increased the elastic modulus. The effect of filler on set, strain, and creep was less pronounced than that of crosslinker; however, its effect on modulus was more pronounced. Increasing the molecular weight of the vinyl polymer had only minor increases in set, strain, and creep and no measurable effect on modulus. Increasing the molecular weight of the vinyl polymer increased percent permanent set, percent strain, and creep and decreased modulus. A plot of 1n percent set versus $1 \mathrm{n}$ percent strain for all samples resulted in a master curve, $1 \mathrm{n} \%$ strain $=0.85+0.86$ $1 \mathrm{n} \%$ set, which fit a linear model at the $95 \%$ level of confidence. Correlation of \% creep and \% set was also found to be represented by a master curve, $\%$ creep $=0.156 \%$ set. Also, the inverse of the elastic modulus, $1 / E$, exhibited a high correlation with $\%$ strain and $\%$ creep. Thus, information about the properties of one of these parameters suggests the values possible for the other three.

The properties of polysulfide, condensation sili- cones, and a polyether were determined by Braden and Inglis (1986) using a torsion pendulum. They demonstrated that no correlation between the mechanical loss tangent and tension set existed but did observe a significant correlation with compression set. They calculated that the mechanical loss tangent should be proportional to the compression set. They propose that this effect results because the compression set test involves shear strain and the elastomers generally function as Hookian materials in shear.

\section{TEAR AND TENSILE PROPERTIES}

Tear properties of rubber impression materials have been reported (Craig, 1986b; Herfort et al., 1978; Sneed et al., 1983; Cook et al., 1984) as well as have their tensile strengths (Cook et al., 1984; Sandrik and Vacco, 1983). Although tear energy values varied among these reports, for a given kind of rubber impression material the values increased from light- to heavy-bodied consistencies. Also, in general, the decreasing order of tear energies, as well as tear strengths, was polysulfide, addition silicones, condensation silicones, and polyethers.

The tensile strengths of the four types of rubber impression materials were in increasing order - polysulfide, condensation silicone, polyether, and addition silicone. However, the ultimate extension ratio was the highest for polysulfides, with the remaining three types having lower and equal values.

\section{DIMENSIONAL CHANGE}

The unrestrained dimensional change after setting has been reported by Craig (1986b), Mansfield and Wilson (1975), Eames et al. (1979), Ohsawa and Jergensen (1983), and Bell et al. (1976). The values show some variation from product to product of the same type, but the decreasing order of dimensional stability is addition silicones, polyethers, polysulfides, and condensation silicones; typical dimensional changes after $24 \mathrm{hr}$ in air of $50 \%$ relative humidity are -0.05 to $-0.1,-0.1,-0.1$ to -0.2 , and -0.4 to $-0.5 \%$, respectively. The dimensional change after seven days for polysulfides and condensation silicones may be as much as -1.3 and $-0.8 \%$, respectively. The dimensional stability of addition silicones and polyethers varies among products. Most addition silicones have values between -0.1 and $-0.2 \%$ after seven days, although some products or viscosities may have values of $-0.4 \%$. Polyethers usually have dimensional changes of $-0.1 \%$ at seven days, although a low- and high-viscosity product (Permadyne) had values of about $-0.25 \%$. As a result of these variations, suggestions that accurate models and dies can be poured from addition silicone or polyether impressions after a week are not true for all products.

The effect of low, medium, and high humidity on the dimensional changes of stored rubber impressions of polysulfides, condensation silicones, and polyethers was reported by Bell et al. (1976). The dimensional change of all three types was affected. The 
standard polysulfide was affected the least, followed by the condensation silicone and polyether. Under conditions of high humidity, the polyether and condensation silicone had positive rather than negative dimensional changes, with values at $72 \mathrm{hr}$ of +0.98 and $+0.24 \%$, respectively. The optimum storage condition for polysulfides was high humidity; for condensation silicone, medium humidity; and for polyether, low humidity.

The coefficient of thermal expansion of addition silicones was measured by Jørgensen (1982b) and was found to be about $150 \times 10^{-6 /}{ }^{\circ} \mathrm{C}$ between $22^{\circ}$ and $37^{\circ} \mathrm{C}$. It was demonstrated (Jørgensen, $1982 \mathrm{~b}$; de Araujo and Jorgensen, 1986) that the shrinkage from mouth to room temperature could be compensated for by heating and pouring models at $37^{\circ} \mathrm{C}$. This procedure resulted in improved accuracy of models.

\section{ACCURACY}

\section{Model Systems}

A variety of laboratory models has been used to evaluate the accuracy of rubber impression materials (Reisbick and Matyas, 1975; Stackhouse, 1975; Stauffer et al., 1976; Marcinak et al., 1980; Lacy et al., 1981a, b; Augsburger et al., 1981; Marcinak and Draughn, 1982; Finger and Ohsawa, 1983; Johnson and Craig, 1985). The ranking of the accuracy of the four types of rubber impression materials varies somewhat among these authors, and it is reasonable to conclude that addition silicones and polyethers are more accurate than condensation silicones and polysulfides. Some of the variations between studies result from the fact that an impression does not change dimensions uniformly in all directions. Johnson and Craig (1985) showed, using a two-post model representing preparations for a 4-unit fixed bridge, that the distance between posts is not sensitive to detection of differences between materials or techniques. The diameter or height of the posts was a better dimension to use to examine differences. In general, improved stone models will have a larger post diameter and a shorter post height than will the master. In addition, the increase in the post diameter will be larger in the buccal-lingual than the mesial-distal direction. These results may be caused by the impression material shrinking toward the tray and away from the post and the free boundary, thus producing a larger diameter but shorter post.

Conclusions reached by Johnson and Craig (1985) were: (1) The diameter of the stone post was larger than that of the master for an addition silicone and a polysulfide, was unchanged for a condensation silicone, and larger for the polyether; (2) the height of the post was shorter than that of the master for all materials, with the addition silicone showing the smallest change; (3) the addition and condensation silicones demonstrated the best recovery as a result of being removed from undercuts and the least change between models from an initial and a second pour; and (4) the addition sili- cone and polyether were least affected, with delays in pouring of one, four, and $24 \mathrm{hr}$.

Two recent papers by Tjan et al. (1986) and Linke et al. (1985) have reported on the accuracy using in vitro methods. The former studies included agar, polysulfide, condensation (putty-wash) and addition silicones, and a polyether. Standard gold castings were used to evaluate the accuracy of dies from the impressions of crowns, MOD's, and occlusal inlays. Agar was less accurate than were silicones and the polyether for making impressions of occlusal or MOD inlays. Agar was less accurate for making crowns than were polysulfides, where crowns were oversize, while the addition silicones gave both over- and undersized crowns. A delay of $24 \mathrm{hr}$ in pouring polysulfide impressions of inlays did not result in a statistically significant difference in accuracy from those poured immediately. However, polysulfide impressions of crowns must be poured as soon as possible to avoid oversize restorations.

A delay in pouring condensation silicone impressions of MOD's and crowns resulted in a decrease in accuracy which was not observed for occlusal inlays.

The polyether and addition silicone impressions were the most stable, with no measurable difference in accuracy of dies found between those poured at $0.5 \mathrm{hr}$ and seven days.

Linke et al. (1985) examined the accuracy of impressions of a light-putty addition silicone, a regular alginate-silicone, a light-regular alginate silicone, an alginate, an agar-alginate, and a light-heavy agar. They found that all materials gave casts with an arch perimeter larger than that of the master. Agar impressions produced significantly less interabutment distortions than did other materials, while the addition-silicone material gave less interabutment distortion than did alginate impressions. The use of a lightregular alginate-silicone did not improve the accuracy. However, they claim that the alginate-silicone and the agar-alginate systems had clinically acceptable accuracy.

\section{Effects of Techniques}

The effect of technique on accuracy has been reported by Gunther and Welsh (1978), Eames and Sieweke (1980), Lehmann and Lindemann (1980), Millstein and Clark (1981), Tjan et al. (1984), Bomberg and Hatch (1984), Valderhaug and Floystrand (1984), Appelbaum and Mehra (1984), de Araujo and Jørgensen (1985), and Johnson and Craig (1986b). The consensus was that for polysulfide the use of a custom tray or a double-mix technique produced more accurate impressions than did a single mix in a stock tray. The putty-wash technique gave the most accurate impression for condensation silicones, while no difference in accuracy was found with addition silicone impressions made with the putty-wash, singlemix, or double-mix technique. However, even for addition silicones the use of a custom tray produced more accurate impressions than did the use of a stock 
tray. The study by de Araujo and Jergensen (1985) demonstrated that increasing the thickness of the impression material reduced the accuracy more than did increasing the severity of undercuts.

A study by Tjan et al. (1984) found no statistical difference in accuracy of condensation silicone putty impressions relined (1) in light-bodied material, or (2) in light- and medium-bodied material, or (3) in a laminated single impression of putty and light-bodied material. However, Bomberg and Hatch (1984) found that corrected polyether or addition silicone impressions were substantially inaccurate compared with an original impression.

\section{Effects of Trays}

The dimensional changes in acrylic tray materials have been reported by Pagniano et al. (1982) and Goldfogel et al. (1985). Dimensional changes in acrylic resins for custom trays varied from -0.08 to $-0.4 \%$ over $24 \mathrm{hr}$, with $90 \%$ of the shrinkage occurring at 8$10 \mathrm{hr}$. Thus, it is recommended that acrylic custom trays should not be used the day of fabrication unless they are placed in boiling water for five min. Acrylic custom trays that have been boiled still shrink $0.06 \%$ in $24 \mathrm{hr}$, and therefore, regardless of the method of tray preparation, impressions should be poured promptly.

Jørgensen (1980) evaluated the viscoelastic properties of base plates for impression trays. Base plates with a thickness of $3 \mathrm{~mm}$ had stiffness similar to that of 0.75 -mm stainless steel; this stiffness was sufficient to prevent clinically significant distortion of the impression.

The retention of elastic impressions in trays was studied by Jørgensen (1979) and Viohl and Nolte (1983). Adhesives were recommended to be used on all trays, even those with perforations. Rapid removal of the impression from the mouth increased the retention between the tray and the impression materials, as did removal in a vertical rather than oblique direction. Also, in general, retention by the tray decreased with increases in flexibility of the impression material.

Fehling et al. (1986) measured the optimum interval between making and using an acrylic custom tray. They measured the dimensional change in mandibular arch-shaped trays made from Fastray and Formatray. Cross-arch changes occurred for six hr; however, they claim that significant changes were observed for only $40 \mathrm{~min}$. They concluded that an aged acrylic impression tray is preferred, and it is acceptable to use a custom tray after $40 \mathrm{~min}$, although it should be poured as soon as conveniently possible.

\section{IMPRESSION TECHNIQUES}

The impression technique used to take impressions of dentulous (Wilson and Werrin, 1982, 1983), partially dentulous (Blatterfein et al., 1980), and edentulous (Koran, 1980; Rihani, 1981) patients has received attention. The use of a double-arch, closed-mouth technique was described, with a double-impression or a single-impression method used, with a triple tray. Stiff and highly accurate impression materials such as polyethers and addition silicones were recommended to assure adequate rigidity, dimensional accuracy, and low permanent deformation. Also, the more rigid trays reduced distortion of the rubber impressions.

Impression techniques to be used in the construction of deep rest distal-extension removable partial dentures have been shown to require a specially prepared custom tray in conjunction with compound, acrylic resin, and polyether. The final impression had firm seats for the abutment castings, proper border extension, and ridge loading. The technique was accurate for semi-precision and precision distal-extension removable partial dentures.

The features involved in making edentulous impressions have been reviewed by Koran (1980). He listed the following as desirable features: (1) healthy and firm mucosa; (2) a low-viscosity impression material; (3) a hydrophilic impression material; and (4) minimal pressure during seating of the impression. Rihani (1981) measured the pressures on the mucosa of the upper-denture-bearing area during the making of an impression; the center of the palate was subjected to the most pressure, which diminished toward the buccal borders.

\section{COMPATIBILITY WITH DIE MATERIALS}

\section{Stone Casts}

Lorren et al. (1976) measured the contact angles of mixes of dental stone on elastic impression materials and found values of about $95^{\circ}, 70^{\circ}, 50^{\circ}$, and $40^{\circ}$ for condensation silicones, polysulfides, polyethers, and hydrocolloids, respectively. They also found a direct relationship between the contact angle and the number of bubbles occurring on casts. Norling and Reisbick (1979) measured the contact angles of saturated calcium sulfate dihydrate solutions to be $80^{\circ}, 97^{\circ}$, and $15^{\circ}$ on polysulfide, silicone, and polyether impressions. When they incorporated non-ionic surfactants into polysulfide and silicone impression materials, the wettability of gypsum mixes increased and the number of surface bubbles decreased. The working time of the silicone was increased; however, the working time of the polysulfide was unchanged, as was the permanent deformation or dimensional change. Unpublished data (Craig, 1986a) on a new hydrophilic addition silicone (new Express) indicate a contact angle of about $60^{\circ}$ for a mix of dental stone.

Wiktorsson and Feder (1983) observed voids on the surfaces of stone casts poured against addition silicones as a result of the release of hydrogen after setting. Manufacturers of products releasing hydrogen recommend delaying pouring of impression in dental stone for one hr to avoid the problem. Morford et al. (1986) showed that subjecting such impressions to 28 inches of vacuum for five $\mathrm{min}$ allows for prompt pouring of dental stone without detrimental effect on 
accuracy. Unpublished data (Craig, 1986a) showed that placing the impression for $10 \mathrm{~min}$ in water near the boiling point also permits prompt pouring of addition silicone impressions without bubbles from hydrogen and with no effect on accuracy if the impression is cooled to room temperature before being poured. Some manufacturers have eliminated the hydrogen evolution problem by incorporating a hydrogen absorber (palladium black, e.g., Exaflex) or eliminating traces of water or hydroxyl groups in the pastes from fillers or polymers (e.g., President).

\section{Epoxy Casts}

Pouring of epoxy casts in addition silicones that release hydrogen should be delayed until the following day, since voids are readily obtained even after four hr or longer (Craig, 1986a), although adequate stone casts can be prepared after a one-hour delay. This difference appears to be related to the slower setting of the epoxy compared with the stone.

Aiach et al. (1984) studied the compatibility and accuracy of epoxy materials with elastic impression materials. Epoxy dies from polyether or addition silicone impressions were 0.1 to $0.15 \%$ smaller than the master at $18 \mathrm{hr}$, with no further change at one week. When the epoxy was poured into a polysulfide impression (Omniflex), the 18-hour values were -0.2 to $-0.23 \%$, and the one-week values were -0.22 to $-0.27 \%$. The detail reproduction and compatibility of epoxy materials with the polyether or addition silicone were excellent.

\section{Electroformed Metals}

Although polysulfides are usually silverplated, Cummins (1975) has described a method for copperplating polysulfides that appears to meet the requirements of clinical accuracy. Vermilyea et al. (1975a, b) found polysulfides much easier to silver-plate than were silicones or polyethers. They also found that vertical shrinkages of silver-plated dies were greater than for stone dies, although the horizontal changes were statistically the same.

Stackhouse (1981a, b) has studied electroforming silver, copper, and nickel on rubber impression materials. Satisfactory platings were obtained with silver on polysulfide, with nickel on condensation silicones, with silver and nickel on polyethers, and with copper on addition silicones. He found that nickel plating on polyethers and condensation silicones gave the greatest accuracy.

Plekavich and Joncas (1983) compared the accuracy of silver dies from polysulfide impressions with stone dies from condensation silicone and polyether impressions by measuring the marginal opening of cemented gold crowns. They found that crowns produced on silver dies from polysulfide impressions had the smallest marginal openings.

\section{BIOCOMPATIBILITY}

Case reports have appeared that involved reactions to some rubber impression materials (Gettleman and
Agranat, 1978; Gettleman et al., 1978; Eliasson and Holte, 1979; van Groeningen and Nater, 1975; Blankenau et al., 1984). Craig (1982) reviewed the tissue reaction to impression materials. The main problem was tearing of thin sections of impression, with these fragments left in contact with tissues for a long time. Location of these fragments by radiographs is difficult except for polysulfides containing lead. The lower tear strengths of polyethers and silicones raise some concern, since fragments will not show up on x-rays. Of all the dental impression materials, only addition silicones did not induce a fibroblast response in cell culture.

Saunders et al. (1982) subdermally injected leadcontaining polysulfide rubber impression material into the abdominal wall cavities of rabbits, and whole blood samples were taken over a period of five weeks. They found no statistical increase in the level of lead compared with pre-operative controls. Klotzer et al. (1983) reported that chemotoxic irritation of the oral mucosa was rarely observed with elastic impression materials. However, lip reactions in the form of herpes simplex efflorescence appeared after contact with known toxic elastomers. They believed that the reaction resulted from irritation by the material rather than from infection.

Imai et al. (1983) evaluated the biocompatibility of condensation polymers in general using a cell culture method and found that cell attachment and growth were affected by chemical structure; in particular, aromatic polyamides exhibited better qualities than did aliphatic polyamides.

Winstock and Warnakulasuriya (1986) reported a case of a polyether impression material as a foreign body at two months. The large number of cholesterol clefts identified suggested that tissue damage had occurred.

\section{CLEANING AND DISINFECTING}

A comparison of conventional and ultrasonic cleaning of polysulfide impressions by Lorton et al. (1978) demonstrated that ultrasonic cleaning was equally as efficient as conventional methods, and no increase in accuracy was observed.

The recent use of disposable surgical gloves to reduce transmission of infectious diseases prompted a study of the effects of these gloves on the setting time of putty-type addition silicone impression materials. Niessen et al. (1986) found that one brand out of five significantly retarded the set from two min to more than five min.

The setting of addition silicone putty has been shown to be retarded when the catalyst and base pastes come into contact with natural latex surgical gloves during mixing. This effect has been shown by Cook and Thomasz (1986) to be minimized when the gloves are thoroughly washed with soapy water and then dried before the putties are mixed. Also, vinyl gloves were found to have a minimal effect. It was proposed that the sulfur compounds used as accelerators and/or surfactants in the manufacture of rubber latex poison 
the chloroplatinic acid catalyst in the addition silicones. If this is the cause, latex gloves manufactured with organic-peroxide accelerators rather than sulfurcontaining systems should correct the problem.

Bergman et al. (1980) and Storer and McCabe (1981) investigated the disinfection of rubber impression materials. An evaluation of polysulfides, polyethers, and condensation and addition silicones with a variety of disinfectants was conducted. They found in some cases that some disinfectants adversely affected impression materials, and therefore care should be used in selection of a satisfactory combination. The smallest dimensional changes were observed for addition silicones with Cidex, Techno-sept, Hibitane, K-644, and Benzalkon. In the study by Storer and McCabe (1981) on silicone, polysulfide, and polyether rubber, they found after 16 hr of disinfection that $2 \%$ glutaraldehyde was the most suitable with silicone and polysulfide with respect to surface detail and accuracy.

\section{FutURE DiRECTIONS}

The use of impression compound and zinc oxideeugenol impression pastes should not change much in the future. The increased use of agar impression material as a result of the development of the agaralginate combination technique should level off and continue at a modest level. Increased development of dustless and higher tear strength alginates should be expected as well as increased efforts to re-formulate alginates to produce products with better reproduction of detail and compatibility with gypsum products. It would appear that polysulfides will continue to lose ground to other rubber impression materials, although modifications in polysulfide polymers - to decrease percent permanent deformation, flow, working time, and setting time, and to increase accuracy-could change this trend. Efforts to develop polyethers as multiviscosity systems should continue, as should efforts to improve single-viscosity systems with substantial shear thinning. In addition, efforts should be made to increase their working time and flexibility. Major changes in condensation silicones would not be expected, with most impressions being taken with the putty-wash combination, although efforts should be made to formulate a hydrophilic material. Continued efforts will be made to develop more effective single-viscosity addition silicone systems, probably by controlling the filler particle size and wettability of the filler by the silicone. Hydrophilic addition silicones should be developed further in order to improve the taking of impressions and pouring of casts. Because of the convenience and reduction in the number of voids, development of automatic mixing systems, static and/or mechanical, will continue. With the development of information on the visible curing composites of the BIS-GMA and urethane diacrylate, the commercial availability of visible-curing rubber impression materials is almost a certainty; the essentially unlimited working time at constant viscosity would be a major advantage for this type of system. The increased emphasis on disinfection of impressions will stimulate the development of systems that will disinfect polyethers without causing problems with dimensional change. Finally, impression materials have improved to such an extent that the accuracy may be controlled more by technique than by the material itself. As a result, one would expect increased emphasis on the development of techniques for the taking of various types of impressions.

\section{REFERENCES}

AIACH, D.; MALONE, W.F.P.; and SANDRIK, J. (1984): Dimensional Accuracy of Epoxy Resins and Their Compatibility with Impression Materials, I Prosthet Dent 52:500-504.

APPELBAUM, E.M. and MEHRA, R.V. (1984): Clinical Evaluation of Polyvinylsiloxane for Complete Denture Impressions, / Prosthet Dent 52:537-539.

APPLEBY, D.C.; COHEN, S.R.; RACOWSKY, L.P.; and MINGLEDORFF, E.B. (1981): The Combined Reversible Hydrocolloid Irreversible Hydrocolloid Impression System: Clinical Application, I Prosthet Dent 46:48-58.

APPLEBY, D.C.; PAMEIJER, C.H.; and BOFFA, J. (1980): The Combined Reversible Hydrocolloid/Irreversible Hydrocolloid Impression System, I Prosthet Dent 44:27-35.

APPLEBY, D.C.; SMITH, W.; LONTZ, J.F.; and MNGLEDORFF, E.B. (1985): Combined Reversible/Irreversible Hydrocolloid Impression Systems: Comparative Analysis, J Prosthet Dent 54:627632.

ARIKAWA, H.; FUIII, K.; KANIE, T.; JOSHIN, K.; INOUE, K.; ONIZUKA, T.; and JIMI, T. (1982): A Method for the Determination of Setting Characteristics of Elastomeric Impression Materials, Dent Mater J 1:67-72.

AUGSBURGER, R.H.; SOELBERG, K.B.; PELZNER, R.B.; BOGDAN, M.S.; and KEMPLER, D. (1981): Accuracy of Casts from Three Impression Materials and Effect of a Gypsum Hardener, Oper Dent 6:70-74.

BELL, J.W.; DAVIES, E.H.; and VON FRALNHOFER, J.A. (1976): The Dimensional Changes of Elastomeric Impression Materials under Various Conditions of Humidity, I Dent 4:73-82.

BERGMAN, B.; BERGMAN, M.; and OLSSON, S. (1985): Alginate Impression Materials, Dimensional Stability and Surface Detail Sharpness Following Treatment with Disinfectant Solutions, Swed Dent J 9:255-262.

BERGMAN, M.; OLSSON, S.; and BERGMAN, B. (1980): Elastomeric Impression Materials. Dimensional Stability and Surface Detail Sharpness Following Treatment with Disinfection Solutions, Swed Dent / 4:161-167.

BLANKENAU, R.J.; KELSEY, W.P.; and CAVEL, W.T. (1984): A Possible Allergic Response to Polyether Impression Material: A Case Report, J Am Dent Assoc 108:609-610.

BLATTERFEIN, L.; KLEIN, I.E.; and MIGLINO, J.C. (1980): A Loading Impression Technique for Semiprecision and Precision Removable Partial Dentures, I Prosthet Dent 43:9-14.

BOMBERG, T.J. and HATCH, R.A. (1984): Correction of Defective Impressions by the Selective Addition of Impression Material, I Prosthet Dent 52:38-40.

BRADEN, M. and INGLIS, A.T. (1986): Visco-elastic Properties of Dental Elastomeric Impression Materials, Biomaterials 7:45-48.

BRUGIRARD, J.-L. (1983): Étude Comparée d'un Nouvel Hydrocolloide Irreversible, Rev Mens Suisse Odonto-stomatol 93:455-462. 
BRUNE, D. and BELTESBREKKE, H. (1978): Levels of Airborne Particles Resulting from Handling Alginate Impression Material, Scand J Dent Res 86:206-210.

CAMPAGNI, W.V.; RIVERA, S.; and DAVIDOFF, S.R. (1985): Simplified Techniques for the Preparation and Use of Reversible Hydrocolloid Impression Material, I Prosthet Dent 54:167-169.

CARLYLE, L.W. III (1983): Compatibility of Irreversible Hydrocolloid Impression Materials with Dental Stones, I Prosthet Dent 49:434-437.

CASWELL, C.W.; VON GOTEN, A.S.; and MENG, T.R. (1986): Volumetric Proportioning Techniques for Irreversible Hydrocolloids: A Comparative Study, J Am Dent Assoc 112:859-861.

COOK, W.D. (1982a): Rheological Studies of the Polymerization of Elastomeric Impression Materiais. I. Network Structure of the Set State, J Biomed Mater Res 16:315-330.

COOK, W.D. (1982b): Rheological Studies of the Polymerization of Elastomeric Impression Materials. Il. Viscosity Measurements, I Biomed Mater Res 16:331-344.

COOK, W.D. (1982c): Rheological Studies of the Polymerization of Elastomeric Impression Materials. III. Dynamic Stress Relaxation Modulus, J Biomed Mater Res 16:345-357.

COOK, W.D.; LIEM, F.; RUSSO, P.; SCHEINER, M.; SIMKISS, G.; and WOODRUFF, P. (1984): Tear and Rupture of Elastomeric Dental Impression Materials, Biomaterials 5:275-280.

COOK, W.D. and THOMASZ, F. (1986): Rubber Gloves and Addition Silicone Materials, Aust Dent J 31:140.

COUNCIL ON DENTAL MATERIALS AND DEVICES (1977): Status Report on Polyether Impression Materials, J Am Dent Assoc 95:126130.

CRAIG, R.G. (1977): A Review of Properties of Rubber Impression Materials, Mich Dent Assoc J 59:254-261.

CRAIG, R.G. (1982): Composition, Characteristics and Clinical and Tissue Reactions of Impression Materials. In: Biocompatibility of Dental Materials, Vol. III, D.C. Smith and D.F. Williams, Eds., Boca Raton, Florida: CRC Press, pp. 227-298.

CRAIG, R.G., Ed. (1985a): Restorative Dental Materials, 7th ed. St. Louis: C.V. Mosby Company.

CRAIG, R.G. (1985b): Evaluation of an Automatic Mixing System for an Addition Silicone Impression Material, I Am Dent Assoc 110:213-215.

CRAIG, R.G. (1986a): Unpublished data.

CRAIG, R.G. (1986b): Additions-vernetzende Silikon-Abdruchmaterialien im Vergleich zu Anderen Elastichen Abdruchmaterialien, Phillip I für Restaurative Zahnmedezin 3:244-256.

CUMMINS, R.L. (1975): A Laboratory Procedure for Copperplating Rubber Base Impressions, J Prosthet Dent 33:342-345.

DAVIS, D.R. and PREBLE, J.S. (1986): Accuracy of a Hydrophilic Irreversible Hydrocolloid/Silicone Impression Material, I Prosthet Dent 55:304-308.

DE ARAUJO, P.A. and JØRGENSEN, K.D. (1985): Effect of Material Bulk and Undercuts on the Accuracy of Impression Materials, J Prosthet Dent 54:791-794.

DE ARAUJO, P.A. and JØRGENSEN, K.D. (1986): Improved ACcuracy by Reheating Addition-reaction Silicone Impressions, 1 Prosthet Dent 55:11-12.

DE ARAUJO, P.A.; JØRGENSEN, K.D.; and FINGER, W. (1985): Viscoelastic Properties of Setting Elastomeric Impression Materials, J Prosthet Dent 54:633-636.

DE FREITAS, J.F. (1980): Potential Toxicants in Alginate Powders, Aust Dent J 15:224-228.

EAMES, W.B. and LITVAK, C.S. (1984): New Irreversible Hydrocolloid Silicone Impression Material, J Prosthet Dent 52:479-484.

EAMES, W.B.; ROGERS, L.B.; WALLACE, S.W.; and SUWAY, N.B. (1978): Compatibility of Gypsum Products with Hydrocolloid Impression Materials, Oper Dent 3:108-112.

EAMES, W.B. and SIEWEKE, J.C. (1980): Seven Acrylic Resins for
Custom Trays and Five Putty-wash Systems Compared, Oper Dent 5:162-167.

EAMES, W.B.; WALLACE, S.W.; SUWAY, N.B.; and ROGERS, L.B. (1979): Accuracy and Dimensional Stability of Elastomeric Impression Materials, J Prosthet Dent 42:159-162.

ELIASSON, S.T. and HOLTE, N.O. (1979): Rubber-base Impression Materials as a Foreign Body. Report of a Case, Oral Surg 48:379-380.

ELLIS, B. and LAMB, D.J. (1981): The Setting Characteristics of Alginate Impression Materials, Br Dent ] 151:343-346.

FEHLING, A.W.; HESBY, R.A.; and PELLEU, G.B., Jr. (1986): Dimensional Stability of Autopolymerizing Acrylic Resin Impression Trays, J Prosthet Dent 55:592-597.

FINGER, W. (1986): Accuracy of Dental Duplicating Materials, Quintessence Dent Tech 10:89-92.

FINGER, W. and OHSAWA, M. (1983): Accuracy of Stone-casts Produced from Selected Addition-type Silicone Impressions, Scand J Dent Res 91:61-65.

FUSAYAMA, T.; KUROSAKI, N.; NODE, H.; and NAKAMURA, M. (1982): A Laminated Hydrocolloid Impression for Indirect Inlays, I Prosthet Dent 47:171-176.

GETTLEMAN, L. and AGRANAT, B.J. (1978): Polysulfide Rubber Foreign Body: Report of a Case, Quintessence Int 10:21-24.

GETTLEMAN, L.; NATHANSON, D.; SHKLAR, G.; BRATHWAITE, W.J., Jr.; DARMIENTO, L.; LEVINE, P.; and JUDES, H. (1978): Preliminary Evaluation of the Histotoxicity and Radiopacity of Lead-containing Elastic Impression Materials, J Am Dent Assoc 96:987-993.

GOLDBERG, A.J. (1974): Viscoelastic Properties of Silicone, Polysulfide, and Polyether Impression Materials, J Dent Res 53:1033-1039.

GOLDFOGEL, M.; HARVEY, W.L.; and WINTER, D. (1985): Dimensional Change of Acrylic Resin Tray Materials, J Prosthet Dent 54:284-286.

GRAJOWER, R.; KAUFMAN, E.; and STERN, N. (1975): Temperature of the Pulp Chamber During Impression Taking of Full Crown Preparations with Modelling Compound, I Dent Res 54:212-217.

GUNTHER, G. and WELSH, S.L. (1978): Evaluation of a Rubberbase Impression Material, J Prosthet Dent 39:95-99.

HAMBROK, H.-J. (1981): Einfluss des Mashinellen Anmischens auf das Abbindeverhalten Elastischer Abformmassen, Dtsch Zahnärztl Z 36:805-810.

HANSSON, O. and EKLUND, J. (1984): A Historical Review of Hydrocolloids and an Investigation of the Dimensional Accuracy of the New Alginates for Crown and Bridge Impressions when Using Stock Trays, Swed Dent / 8:81-95.

HARCOURT, J.K. (1978): A Review of Modern Impression Materials, Aust Dent I 23:178-186.

HATTAB, F. and FROSTELL, G. (1980): The Release of Fluoride from Two Products of Alginate Impression Materials, Acta Odontol Scand 38:385-395.

HATTAB, F. and LINDEN, L.- $\AA$. (1985): Diffusion of Fluoride from Alginate Compared with Other Topical Fluoride Agents, Scand I Dent Res 93:269-275.

HERFORT, T.W.; GERBERICH, W.W.; MACOSKO, C.W.; and GOODKIND, R.J. (1977): Viscosity of Elastomeric Impression Materials, I Prosthet Dent 38:396-404.

HERFORT, T.W.; GERBERICH, W.W.; MACOSKO, C.W.; and GOODKIND, R.J. (1978): Tear Strength of Elastomeric Impression Materials, J Prosthet Dent 39:59-62.

HERRING, H.W.; TAMES, M.A.; and ZARDIACKAS, L.D. (1984) Comparison of the Dimensional Accuracy of a Combined Reversible/irreversible Hydrocolloid Impression System with other Commonly Used Impression Materials, J Prosthet Dent 52:795-799.

HOLLINGER, J.O.; LORTON, L.; KRANTZ, W.A.; and CON NELLY, M. (1984): A Clinical and Laboratory Comparison of 
Irreversible Hydrocolloid Impression Techniques, J Prosthet Dent 51:304-309.

IMAI, Y.; WATANABE, A.; and MASUHARA, E. (1983): Structure-biocompatibility Relationship of Condensation Polymers, J Biomed Mater Res 17:905-912.

INOUE, K. and WILSON, H.J. (1978a): Viscoelastic Properties of Elastomeric Impression Materials. II: Variation of Rheological Properties with Time, Temperature and Mixing Proportions, I Oral Rehabil 5:261-267.

INOUE, K. and WILSON, H.J. (1978b): Viscoelastic Properties of Elastomeric Impression Materials. III: The Elastic Recovery after Removal of Strains Applied at the Setting Time, ] Oral Rehabil $5: 323-327$

JARVIS, R.G. and EARNSHAW, R. (1980): The Effects of Alginate Impressions on the Surface of Cast Gypsum. I. The Physical and Chemical Structure of the Cast Surface, Aust Dent J 25:349-356.

JARVIS, R.G. and EARNSHAW, R. (1981): The Effect of Alginate Impressions on the Surface of Cast Gypsum. II. The Role of Sodium Sulphate in Incompatibility, Aust Dent I 26:12-17.

JOHNSON, G.H. and CRAIG, R.G. (1985): Accuracy of Four Types of Rubber Impression Materials Compared with Time of Pour and a Repeat Pour of Models, J Prosthet Dent 53:484-490.

IOHNSON, G.H. and CRAIG, R.G. (1986a): Accuracy and Bond Strength of Combination Agar/alginate Hydrocolloid Impression Materials, I Prosthet Dent 55:1-6.

JOHNSON, G.H. and CRAIG, R.G. (1986b): Accuracy of Addition Silicones as a Function of Technique, J Prosthet Dent 55:197-203.

JØRGENSEN, K.D. (1979): Retention of Elastiske Aftryksmaterialer. I. Aftrykssker, Tandlaegebladet 83:465-478.

JØRGENSEN, K.D. (1980): Basisplader til Aftryksskeer: Elastiskplastiske Egenskaber, Tandlaegebladet 84:491-494.

JORGENSEN, K.D. (1982a): Praecisionen af Reversible og Irreversible Hydrokolloider of af Additionspolymeriserende Silikone Anvendt som Aftryksmaterialer i Krone- og Indlaegsteknikken, Tandlaegebladet 86:626-631.

JØRGENSEN, K.D. (1982b): Thermal Expansion of Addition Polymerization (Type II) Silicone Impression Materials, Aust Dent J 27:377-81.

KALOYANNIDES, T.M. and CHRISTIDOU, L. (1975): Elasticity of Impression Materials: IV. Permanent Deformation as a Function of Time, J Dent Res 54:168-173.

KISHIMOTO, M.; SHILLINGBURG, H.T., Jr.; and DUNCANSON, M.G., Jr. (1980): A Comparison of Six Impression Syringes, J Prosthet Dent 43:546-551.

KLOTZER, W.T.; BEN-UR, Z.; and BONN, B. (1983): Zur Toxizität Elastomerer Abformmaterialien, Dtsch Zahnärztl Z 38:1020-1023.

KNIBBS, P.J. and PINEY, M.D. (1985): An Assessment of the Relative Dustiness of Different Alginate Impression Materials Under Simulated Working Conditions, Br Dent J 158:171-176.

KORAN, A., III (1980): Impression Materials for Recording the Denture Bearing Mucosa, Dent Clin N Am 24:97-111.

KORAN, A., III: POWERS, J.M.; and CRAIG, R.G. (1977): Apparent Viscosity of Materials Used for Making Edentulous Impressions, J Am Dent Assoc 95:75-79.

KOSKI, R.E. (1977): Comparative Study of Selected Alginate Materials and Devices, I Am Dent Assoc 94:713-716.

LACY, A.M.; BELLMAN, T.; FUKUI, H.; and JENDRESEN, M.D. (1981a): Time-dependent Accuracy of Elastomer Impression Materials. Part I: Condensation Silicones, J Prosthet Dent 45:209-215.

LACY, A.M.; FUKUI, H.; BELLMAN, T.; and JENDRESEN, M.D. (1981b): Time-dependent Accuracy of Elastomer Impression Materials. Part II: Polyether, Polysulfides, and Polyvinylsiloxane, ] Prosthet Dent 45:329-333.

LeCOMPTE, E.J. and WHITFORD, G.M. (1981): The Biologic Availability of Fluoride from Alginate Impressions and APF Gel Applications in Children, I Dent Res 60:776-780.
LEHMANN, K.M. and BEHREND, G. (1984): Die Wiedergabe des Abstandes von Brückenpfeilern Durch Reversibles Hydrokolloid, Dtsch Zahnärztl Z 39:876-879.

LEHMANN, K.M. and LINDEMANN, J. (1980): Die Wiedergabe des Pfeilerabstandes bei der Abformung fur Festsitzenden Zahnersatz, Dtsch Zahnärztl Z 35:537-539.

LINKE, B.A.; NICHOLLS, J.I.; and FAUCHER, R.R. (1985): Distortion Analysis of Stone Casts Made from Impression Materials, J Prosthet Dent 54:794-802.

LORREN, R.A.; SALTER, D.I.; and FAIRHURST, C.W. (1976): The Contact Angles of Die Stone on Impression Materials, J Prosthet Dent 36:176-180.

LORTON, L.; PHILLIPS, R.W.; and SWARTZ, M.L. (1978): The Effect of Ultrasonic Cleaning Methods on Rubber Base Impression Materials, J Dent Res 57:939.

MANSFIELD, M.A. and WILSON, H.J. (1975): Elastomeric Impression Materials, Br Dent J 139:267-272.

MARCINAK, C.F. and DRAUGHN, R.A. (1982): Linear Dimensional Changes in Addition Curing Silicone Impression Materials, J Prosthet Dent 47:411-413.

MARCINAK, C.F.; YOUNG, F.A.; DRAUGHN, R.A.; and FLEMMING, W.R. (1980): Linear Dimensional Changes in Elastic Impression Materials, J Dent Res 59:1152-1155.

MCCABE, J.F. and BOWMAN, A.J. (1981): The Rheological Properties of Dental Impression Materials, Br Dent J 151:179-183.

MCCABE, J.F. and STORER, R. (1980): Elastomeric Impression Materials. The Measurement of Some Properties Relevant to Clinical Practice, Br Dent / 149:73-79.

MCCABE, J.F. and WILSON, H.J. (1978): Addition Curing Silicone Rubber Impression Materials. An Appraisal of Their Physical Properties, Br Dent J 145:17-20.

MENDEZ, A.J. (1985): The Influence of Impression Trays on the Accuracy of Stone Casts Poured from Irreversible Hydrocolloid Impressions, J Prosthet Dent 54:383-388.

MILLER, M.W. (1975): Syneresis in Alginate Impression Materials, Br Dent j 139:425-430.

MILLSTEIN, P.L. and CLARK, R.E. (1981): Differential Accuracy of Silicone-body and Self-curing Resin Interocclusal Records and Associated Weight Loss, I Prosthet Dent 46:380-384.

MOOR, T.L. (1985): Reproducibility of Dispensing One Brand of Irreversible Hydrocolloid Powder by Seven Methods, I Prosthet Dent 54:144-145.

MORFORD, H.T.; TAMES, R.R.; and ZARDIACKAS, L.D. (1986): Effects of Vacuum and Pressure on Accuracy, Reproducibility, and Surface Finish of Stone Casts Made from Polyvinyl Siloxane, J Prosthet Dent 55:466-470.

MORRIS, I.C.; KHAN, Z.; and FIELDS, H., Jr. (1983): Effect on Surface Detail of Casts When Irreversible Hydrocolloid was Wetted Before Impression Making, I Prosthet Dent 49:328-330.

MOSKOWITZ, M.E.; LOFT, G.H.; and REYNOLDS, J.M. (1984): Using Irreversible Hydrocolloid to Evaluate Preparations and Fabricate Temporary Immediate Provisional Restorations, ) Prosthet Dent 51:330-333.

NIESSEN, L.C.; STRASSLER, H.; LEVINSON, P.D.; WOOD, G.; and GREENBAUM, J. (1986): Effect of Latex Gloves on Setting Time of Polyvinylsiloxane Putty Impression Material, I Prosthet Dent 55:128-129.

NORLING, B.K. and REISBICK, M.H. (1979): The Effect of Nonionic Surfactants on Bubble Entrapment in Elastomeric Impression Materials, I Prosthet Dent 42:342-347.

OHSAWA, M. and JØRGENSEN, K.D. (1983): Curing Contraction of Addition-type Silicone Impression Materials, Scand J Dent Res 91:51-55.

OLSSON, S.; BERGMAN, B.; and BERGMAN, M. (1982): Zinc Oxide-Eugenol Impression Materials. Dimensional Stability and 
Surface Detail Sharpness Following Treatment with Disinfection Solutions, Swed Dent J 6:177-180.

OTANI, H.; ADACHI, M.; and KANEMATSU, Y. (1985): Surface Reproduction of pH-adjusted Alginate Impression Materials, Dent Mater 1:58-60.

OWEN, C.P. (1986): An Investigation into the Compatibility of Some Irreversible Hydrocolloid Impression Materials and Dental Gypsum Products. Part 1. Capacity to Record Grooves on the International Standard Die, J Oral Rehabil 13:93-103.

PAGNIANO, R.P.; SCHEID, R.C.; CLOWSON, R.L.; DAGEFOERDE, R.O.; and ZARDIACKAS, L.D. (1982): Linear Dimensional Change of Acrylic Resins Used in the Fabrication of Custom Trays, J Prosthet Dent 47:279-283.

PHILLIPS, R.W., Ed. (1982): Skinner's Science of Dental Materials, 8th ed., Philadelphia: W.B. Saunders Company.

PLEKAVICH, E.J. and JONCAS, J.M. (1983): The Effect of Impression-Die Systems on Crown Margins, J Prosthet Dent 49:772-776.

REISBICK, M.H.; GARRETT, R.; and SMITH, D.D. (1982): Some Effects of Device Versus Handmixing of Irreversible Hydrocolloids, J Prosthet Dent 47:92-94.

REISBICK, M.H. and MATYAS, J. (1975): The Accuracy of Highly Filled Elastomeric Impression Materials, J Prosthet Dent 33:67-72.

RIHANI, A. (1981): Pressures Involved in Making Upper Edentulous Impressions, J Prosthet Dent 46:610-614.

SANDRICK, J.L. and SARNA, T. (1980): Temperature of Elastomeric Impression Materials while Setting in the Mouth, J Dent Res 59:1985-1986.

SANDRICK, J.L. and VACCO, J.L. (1983): Tensile and Bond Strength of Putty-wash Elastomeric Impression Materials, J Prosthet Dent 50:358-361.

SAUNDERS, T.R.; PIERSON, W.P.; and MILLER, R.I. (1982): Effect of Lead-containing Elastic Impression Materials on Whole Blood Lead Levels, J Prosthet Dent 47:209-211.

SAWYER, H.F.; SANDRIK, J.L.; and NEIMAN, R. (1976): Accuracy of Casts Produced from Alginate and Hydrocolloid Impression Materials, J Am Dent Assoc 93:806-808.

SCRABECK, J.G.; EAMES, W.B.; and HICKS, M.J. (1986): Spatulation Methods and Porosities in Investments and Impression Material, J Prosthet Dent 55:332-334.

SNEED, W.D.; MILLER, R.; and OLSON, J. (1983): Tear Strength of Ten Elastomeric Impression Materials, J Prosthet Dent 49:511513.

STACKHOUSE, J.A., Jr. (1975): A Comparison of Elastic Impression Materials, J Prosthet Dent 34:305-313.

STACKHOUSE, J.A., Jr. (1981a): Impression Materials and Electrodeposits. Part I: Impression Materials, J Prosthet Dent 45:44-48.

STACKHOUSE, J.A., Jr. (1981b): Impression Materials and Electrodeposits. Part II: Electrodeposits, J Prosthet Dent 45:146-151.

STACKHOUSE, J.A., Jr. (1983): Voids in a Mixed Elastomeric Impression Material, J Prosthet Dent 50:762-766.

STACKHOUSE, J.A., Jr. (1985): Relationship of Syringe-tip Diameter to Voids in Elastomeric Impressions, J Prosthet Dent 53:812 815.

STANNARD, J.G. and CRAIG, R.G. (1979): Modifying the Setting Rate of an Addition-type Silicone Impression Material, I Dent Res 58:1377-1382.

STANNARD, J.G. and SADIGHI-NOURI, M. (1986): Retarders for Polyvinylsiloxane Impression Materials: Evaluation and Recommendations, J Prosthet Dent 55:7-10.

STAUFFER, J.-P.; MEYER, J.-M.; and NALLY, J.-N. (1976): Ac- curacy of Six Elastic Impression Materials Used for Completearch Fixed Partial Dentures, J Prosthet Dent 35:407-415.

STORER, R. and McCABE, J.F. (1981): An Investigation of Methods Available for Sterilising Impressions, Br Dent ] 151:217-219.

TJAN, A.H.L.; WHANG, S.B.; and TJAN, A.H. (1984): Clinically Oriented Assessment of the Accuracy of Three Putty-wash Silicone Impression Techniques, I Am Dent Assoc 108:973-975.

TJAN, A.H.L.; WHANG, S.B.; TJAN, A.H.; and SARKISSIAN, R. (1986): Clinically Oriented Evaluation of the Accuracy of Commonly Used Impression Materials, I Prosthet Dent 56:4-8.

TOLLEY, L.G. and CRAIG, R.G. (1978): Viscoelastic Properties of Elastomeric Impression Materials: Polysulphide, Silicone and Polyether Rubbers, J Oral Rehabil 5:121-128.

VALDERHAUG, J. and FLOYSTRAND, F. (1984): Dimensional Stability of Elastomeric Impression Materials in Custom-made and Stock Trays, I Prosthet Dent 52:514-517.

VAN GROENINGEN, G. and NATER, J.P. (1975): Reactions to Dental Impression Materials, Contact Derm 1:373-376.

VERMILYEA, S.G.; POWERS, J.M.; and CRAIG, R.G. (1975a): Polyether, Polysulfide and Silicone Rubber Impression Materials. Part 1: Quality of Silverplated Dies, Mich Dent Assoc 1 57:371404.

VERMILYEA, S.G.; POWERS, J.M.; and CRAIG, R.G. (1975b): Polyether, Polysulfide and Silicone Rubber Impression Materials. Part 2: Accuracy of Silverplated Dies, Mich Dent Assoc I $57: 405-410$.

VIOHL, J. and NOLTE, T. (1983): Haftung von Elastomeren Absormmaterialien am Abdruckloffel, Dtsch Zahnärztl Z 38:13-17.

WHITFORD, G.M. and EKSTRAND, J. (1980): Systemic Absorption of Fluoride from Alginate Impression Material in Humans, J Dent Res 59:782-785.

WIKTORSSON, G. and FEDER, D. (1983): Quality of Stone Dies Produced by Different Impression Materials. A Comparative Study of Impression Techniques, Swed Dent ] 7:77-83.

WILLIAMS, D.F. and CUNNINGHAM, J. (1979): Materials in Clinical Dentistry, Oxford: Oxford University Press.

WILLIAMS, J.R. (1984): Physical Properties of Addition Silicones as a Function of Composition. Master's Thesis, Ann Arbor, University of Michigan.

WILLIAMS, J.R. and CRAIG, R.G. (1984): Physical Properties of Addition Silicones as a Function of Composition, Dent Mat $G p$ Microfilm, 62nd General Session IADR, Dallas, TX, Mar. 15-18; J Oral Rehabil, in press.

WILLIAMS, K.R. and WATKINS, H. (1983): Comparison of the Structure and Properties of Conventional and Siliconised Alginates, Br Dent J 155:415-418.

WILSON, E.G. and WERRIN, S.R. (1982): A Versatile Impression Technique for Dental Castings, Quintessence Int 12:1307-1313.

WILSON, E.G. and WERRIN, S.R. (1983): Double Arch Impressions for Simplified Restorative Dentistry, ] Prosthet Dent 49:198202.

WINSTOCK, D. and WARNAKULASURIYA, S. (1986): Impression Material Presenting in the Maxillary Antrum as a Foreign Body, Br Dent J 160:54-55.

WOODWARD, J.D.; MORRIS, J.C.; and KHAN, Z. (1985): Accuracy of Stone Casts Produced by Perforated Trays and Nonperforated Trays, J Prosthet Dent 53:347-350.

WOODY, R.D.; HUGET, E.F.; and CUTRIGHT, D.E. (1977): Characterization of Airborne Particles from Irreversible Hydrocolloids, I Am Dent Assoc 94:501-504. 